View Article Online / Journal Homepage / Table of Contents for this issue

MILLS AND BARR : PRECIPITATION OF THE ALUMS, ETC. 341

LIII.-On the Precipitation of the Alums by Sodic Carbonate.

By Edmund J. Mills, D.Sc., F.R.S., and R. L. BarR.

ThE behaviour of a solution of alum towards sodic carbonate is a subject of considerable theoretical as well as technical importance, and extremely complicated in its nature. It therefore appeared to us that the following research-dealing, as it does, with a specific phase of the general investigation-might be of interest to chemists.

We have been induced to submit it at this time to the Society, 
partly because it is complete in itself, and partly becauso circum. stances do not permit of our pursuing it further.

The particular alums we employed were potassio-aluminic and potassio-chromic alum.

\section{Precipitation of Potassio-aluminic Alum.}

The alum employed in our experiments was an excellent commercial sample, containing scarcely perceptible traces of iron, and yielding very nearly the amount of alumina indicated by theory. An aqueous solution of this was prepared of such verified strength as to contain 1 per cent. by calculation of aluminic sulphate, or 0.2982 gram alumina in 100 c.c.

The solution of sodic carbonate was made from cleaned sodium, by reaction in a silver vessel with water, carbonation with excess of purified carbon dioxide, and evaporation at $100^{\circ}$, the residue being dissolved in such a proportion of water as to constitute a liquid of 0.93038 per cent. strength. This strength, considered with reference to that of the alum solution, is as $3 \mathrm{Na}_{2} \mathrm{CO}_{3}: \mathrm{Al}_{2}\left(\mathrm{SO}_{4}\right)_{3}$, in equal volumes.

A precipitation experiment was carried out as follows: The bottles containing the reagents, another holding distilled water, and a dry beaker, were placed in a trongh of running water until their temperature became sensibly constant. The requisite quantity of sodic solution was then introduced, with frequent stirring, into the beaker; next, sufficient water to make up an invariable volume of 100 c.c.; and lastly and always, 100 c.c. of alum solution. The mixture was well agitated with a thermometer (whose indication was observed) and left at rest, under the same conditions, for exactly an hour. At. the end of this time it was filtered as rapidly as possible with the aid of suction. The precipitate was washed, first with cold, and subsequently with hot water, until the precipitate was free from sulphate; it was then re-dissolved as chloride, and precipitated by ammonia. The results of our experiments are recorded in the following table :-

\section{TABLe I.}

\begin{tabular}{|c|c|c|c|c|}
\hline $\begin{array}{c}\text { Potash alum } \\
\text { taken in c.c. } \\
100\end{array}$ & $\begin{array}{c}\text { Sodic carbonate } \\
\text { taken in c.c. } \\
20\end{array}$ & $\begin{array}{r}\text { Alun } \\
\text { precip } \\
0.0074\end{array}$ & $\begin{array}{l}\text { ina } \\
\text { iated. } \\
\text { gram. }\end{array}$ & $\begin{array}{c}\text { Temperature. } \\
9 \cdot 8^{\circ}\end{array}$ \\
\hline ", & 30 & 0.0386 & $"$ & $8 \cdot 8$ \\
\hline "थ & 40 & 0.0979 & ", & 9.8 \\
\hline "ֶ & 45 & $0 \cdot 1331$ & $"$ & $9 \cdot 8$ \\
\hline " & 50 & $0 \cdot 1664$ & , & $9 \cdot 9$ \\
\hline " & 60 & $0 \cdot 219 !$ & , & $8 \cdot 8$ \\
\hline ", & 65 & 0.2472 & ", & $10 \cdot 8$ \\
\hline , & 70 & 0.2679 & $"$ & 102 \\
\hline ", & 80 & 0.3039 & ", & $8 \cdot 9$ \\
\hline
\end{tabular}


We noticed in the course of this work that the first filtrate became turbid on standing, where lower quantities of carbonate had been added.

\section{Precipitation of Potassio-chromic Alum.}

This alum was prepared by ourselves, and recrystallised from water below $50^{\circ} \mathrm{C}$, , until it furnished on analysis very nearly the theoretical quantity of chromic oxide. The standard solution of this contained $1 \cdot 1518$ per cent. chromic sulphate, corresponding to $0 \cdot 4474$ gram oxide in 100 c.c. This strength, considered with reference to that of the sodic solution, is as $\mathrm{Cr}_{2}\left(\mathrm{SO}_{4}\right)_{3}: 3 \mathrm{Na}_{2} \mathrm{CO}_{3}$, in equal volumes.

The experiments were carried out exactly as in the case of the preceding alum; their results are stated in Table II.

\section{TABLE II.}

\begin{tabular}{|c|c|c|c|}
\hline $\begin{array}{c}\text { Chrome alum } \\
\text { in c.c. } \\
100\end{array}$ & $\begin{array}{c}\text { Sodic carbo- } \\
\text { nate in c.c. } \\
60\end{array}$ & $\begin{array}{c}\text { Weight of } \\
\text { chromic oxide } \\
\text { in precipitate. } \\
0.0146\end{array}$ & $\begin{array}{c}\text { Temperature: } \\
7 \cdot 7^{\circ}\end{array}$ \\
\hline - & 65 & $0 \cdot 0491$ & $7 \cdot 9$ \\
\hline 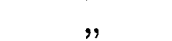 & 70 & 0.0979 & $7 \cdot 7$ \\
\hline$"$ & 75 & $0 \cdot 1520$ & $8 \cdot 7$ \\
\hline "ฯ & 85 & 0.2602 & $8 \cdot 7$ \\
\hline " & 95 & 0.3328 & $7 \cdot 9$ \\
\hline ", & 100 & 0.3566 & $6 \cdot 3$ \\
\hline ", & 110 & 0.3894 & $5 \cdot 8$ \\
\hline
\end{tabular}

The first filtrate always became slightly turbid on standing.

\section{Discussion.}

On plotting out our results, we soon found reason to believe that the precipitation of an alum by sodic carbonate-as we performed it, at least-takes place in three stages. First, a considerable addition of carbonate is necessary before any precipitation takes place at all; secondly, there is precipitation according to a continuous law, until about half the alum has been thrown down; and thirdly, the precipitation is proceeded with according to the previous law, but with altered constants.

Guldberg and Waage (Études sur les Affinités chimiques, 63) have given a particular relation between precipitant and precipitate, which we believe to be general, and which, with a necessary linear alteration, we have found well adapted to our numerical results.

a-Potassio-aluminic Alum.- - In the stage antecedent to precipitation, 
very nearly 19 c.c. are required. The first stage of precipitation is represented by the equation:

$$
y=\frac{0 \cdot 1491-0.0053250(47-x)}{1+0 \cdot 025380(47-x)},
$$

in which $y$ is the weight of alumina precipitated, $x$ the number of cubic centimeters of carbonate taken in any one experiment, $0 \cdot 1491$ represents one-half of the total alumina constantly present in the solution, and 4.7 is the number of cubic centimeters of carbonate required to complete the semi-precipitation.

In the second stage we have-

$$
y=0.149 .1+\frac{0.1491-0.0045182(80-x)}{1-0.0098153(80-x)},
$$

where the general symbols have the same meaning as before. The number of cubic centimeters of carbonate required for complete precipitation of all the alumina is 80 .

Thus, our solution just began to yield a precipitate when the aluminic sulphate and carbonate were nearly in the ratio-

$$
\mathrm{Al}_{2}\left(\mathrm{SO}_{4}\right)_{3}: \frac{3}{5}\left(\mathrm{Na}_{2} \mathrm{CO}_{3}\right) \text {; }
$$

it was about half precipitated when the ratio $\mathrm{Al}_{2}\left(\mathrm{SO}_{4}\right)_{3}: \frac{3}{2}\left(\mathrm{Na}_{2} \mathrm{CO}_{3}\right)$ was attained; and it was completely precipitated in the proportion $\mathrm{Al}_{2}\left(\mathrm{SO}_{4}\right)_{3}: \frac{12}{5} \cdot\left(\mathrm{Na}_{2} \mathrm{CO}_{3}\right)$. This last fact is of considerable economical importance, and probably even less carbonate would have sufficed had our solutions been more concentrated.

We subjoin a numerical comparison of theory with experiment:-

$$
\text { TABLE III. }
$$

\section{Carbonate in c.c.}

20

30

40

45

47

50

60

65

70

80
Alumina precipitated. 0.0074 gram. 0.0386 , 0.0979, $0 \cdot 1331$, $0 \cdot 1491$, $0 \cdot 1664$, 0.2199, 0.2472, 0.2679 , 0.3039 ,
Alumina precipitated, calc. 0.0032 gram.

0.0409 , 0.0950 , 0.1318 , $0 \cdot 1491$, $0 \cdot 1684$, 0.2223 ,

0.2445 , 0.2644 , 0.2982 ,

Probable error of a single comparison, 0.0025 gram.

$\beta$-Potassio-chromic Alum.-The stage antecedent to precipitation requires, in this case, no less than 59 c.c. of the sodic reagent. The 
WARINGTON: DETERMINATION OF NITRIC ACID, ETC. 345

subsequent stages are represented by the following equations in order :-

$$
\begin{gathered}
y=\frac{0.2237-0.0097686(81.7-x)}{1+0.010083(81 \cdot 7-x)}, \\
y=0.2237+\frac{0.2237-0.0039040(139-x)}{1-0.011873(139-x)},
\end{gathered}
$$

Thus, our solution just began to yield a precipitate when the sulphate and carbonate were nearly in the ratio $\mathrm{Cr}_{2}\left(\mathrm{SO}_{4}\right)_{3}: 2 \mathrm{Na}_{2} \mathrm{CO}_{3}$; the stage of semi-precipitation was approximately marked by the ratio $\mathrm{Cr}_{2}\left(\mathrm{SO}_{4}\right)_{3}: \frac{12}{5}\left(\mathrm{Na}_{2} \mathrm{CO}_{3}\right)$. The completion of precipitation would have required 139 c.c. carbonate. This quantity we could not hope to comprise within our conditions, though we have successfully ventured as far as 110 c.c.

\begin{tabular}{|c|c|c|c|c|}
\hline $\begin{array}{c}\text { Carbonate } \\
\text { in c.e. } \\
60\end{array}$ & \multicolumn{2}{|c|}{$\begin{array}{l}\text { Chromic oxide } \\
\text { precipitated. } \\
0.0146 \text { gram. }\end{array}$} & \multicolumn{2}{|c|}{$\begin{array}{l}\text { Chromic oxide } \\
\text { calculated. }\end{array}$} \\
\hline 6.5 & 0.0491 & 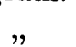 & 0.0519 & $y$ \\
\hline 70 & 0.0979 & , & 0.0979 & $"$ \\
\hline 75 & 0.1520 & , & 0.1483 & , \\
\hline 85 & 0.2602 & , & $0 \cdot 2596$ & , \\
\hline 9.5 & 0.3328 & ," & 0.3325 & , \\
\hline 100 & 0.3566 & , & 0.3568 & , \\
\hline 110 & 0.3894 & ", & 0.39 .20 & , \\
\hline
\end{tabular}

TABLE IV.

Probable error of a single comparison, 0.0019 gram.

The accompanying drawing, which has been constructed from the equations, exhibits the entire course of precipitation of both oxides. 
CUB. CENT. CARBONATE

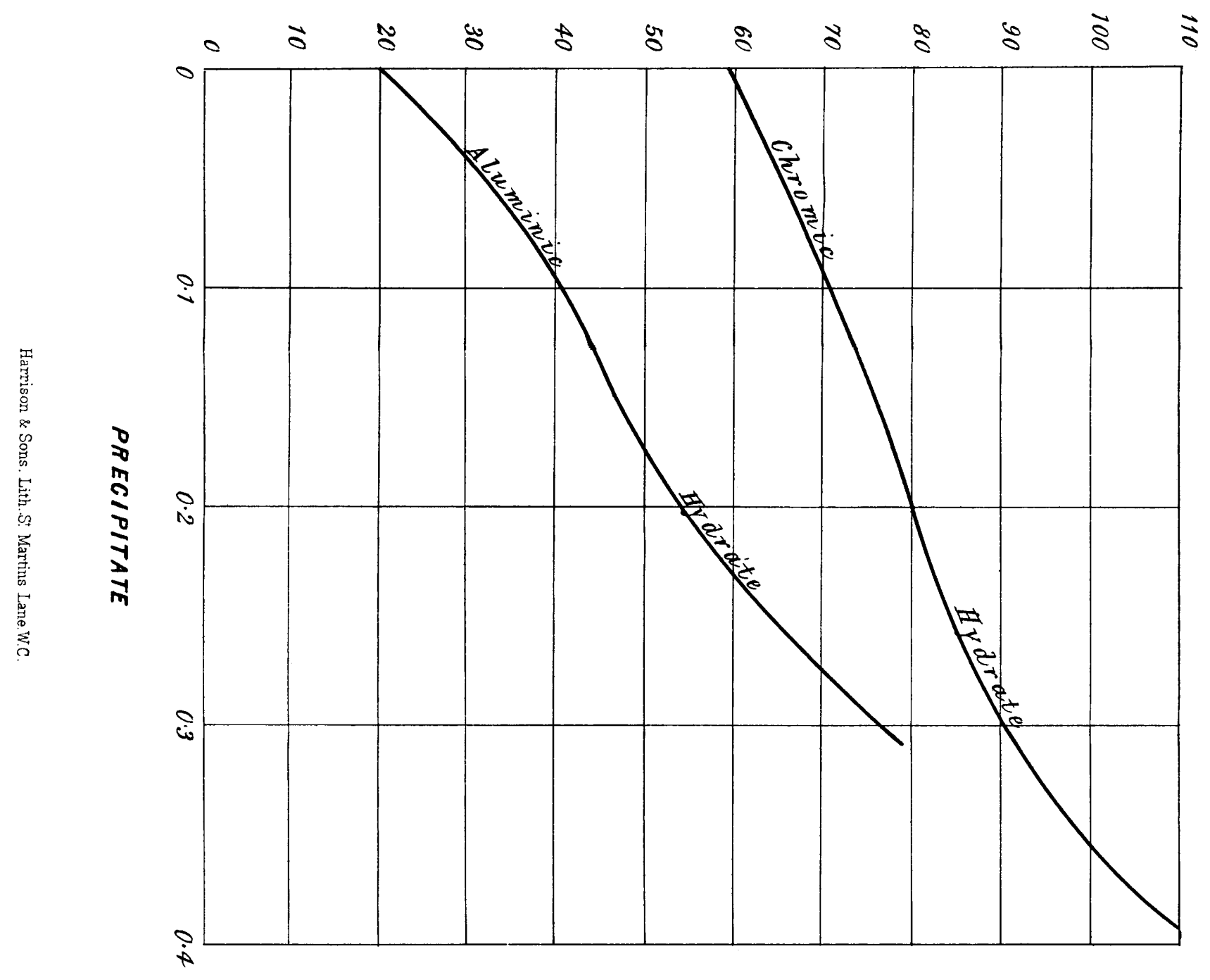

हิ 